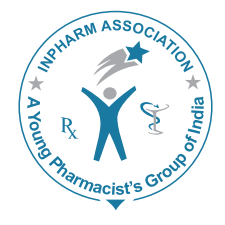

\section{Health-related Quality of Life Measurement}

Sir,

Measurements are very important in all activities so as to differentiate and rank among themselves. Health care services are generally administered by professionals but are received by patients and so they may have different perceptions. Doctors who are providers of health care are almost satisfied with the clinical outcomes. On the contrary, the patients are more sensitive to the treatments in terms of whether it makes any difference for them as for the quality of life. They also wish if the treatments could be economically affordable. Traditionally, health care was viewed successful if clinical goals were met, and seldom point of view of the patients' choices was given any importance. According to the WHO definition of health states, health is a state of complete physical, mental and social well-being and not merely the absence of disease or infirmity. ${ }^{[1]}$ Hence, patients' perception about the status of their current health and its direct measurement has become vital among researchers measuring outcomes. Measuring patients' perception and the extent to which they can actually function in their daily activities are very important when the main objective of treatment is to improve how the patient feels.

The technique used to incorporate the effects of treatments and diseases from patients' view point is to use health-related quality of life (HRQoL) measures. HRQoL is a broad theoretical construct developed to explain and organize measures concerned with the evaluation of health status, values and perceived levels of satisfaction and general wellbeing with respect to either specific health condition or life as a whole from individual's perspective. ${ }^{[2]}$ Since many domains of HRQoL cannot be observed directly, HRQoL instruments are developed to measure the broad perception of health (physical, mental, and social well-being) known as domains, by explaining the extent of difficulty with activities of daily living (including work, recreation, and household management) and how these difficulties affect relationships with family, friends, and social groups. When measuring HRQoL, it is important that the instrument selected measures the health dimensions relevant to that particular set of patients. HRQOL instruments are commonly available as disease specific and generic instruments. A disease-specific instrument is broadly designed to collect patients' perception about specific aspects of health which is affected by the specific disease, while generic instruments measure general health, including physical symptoms, function, and emotional dimensions of health relevant to all health states, including healthy individuals. ${ }^{[3]}$

Scarce availability of resources in society compels decision makers to balance the benefits and risks of treatment when they make decisions for patients. One must also take into account that benefits gained are worthy as the resources that must be spent in providing them. When the resources of family are limited, it has to forgo other benefits, which necessitate the need for economic analysis to aid in informed decision making. The HRQoL instruments can be used to study the benefits gained or perceived by the patients against the resources consumed, thus helping in economic evaluation.

\section{Muragundi PM, Tumkur AM, Shetty RK ${ }^{1}$, Naik AN}

Department of Pharmacy Management, Manipal College of Pharmaceutical Sciences, ${ }^{1}$ Department of Cardiology, Kasturba Medical College, Manipal University, Manipal, Karnataka, India Address for correspondence: Dr. Anantha N Naik;
E-mail: anantha1232000@gmail.com

\section{REFERENCES}

1. World Health Organization. 2006. Constitution of the World Health Organization - Basic Documents, 45 ${ }^{\text {th }}$ edition, Supplement, October 2006.

2. Berger ML, Bingefors K, Hedblom EC, Pashos CL, Torrance GW. Health Care Cost, Quality and Outcomes: ISPOR Book of Terms. Lawrenceville, NJ: ISPOR; 2003. p. 129-31.

3. Jackowski D, Guyatt G. A guide to health measurement. Clin Orthop Relat Res 2003;413:80-9.

\begin{tabular}{|l|l|}
\hline \multicolumn{2}{|c|}{ Access this article online } \\
\hline Quick Response Code: & \\
\hline & Website: \\
\hline & www.jyoungpharm.in \\
& DOI: \\
\hline
\end{tabular}

